\title{
Avaliação de patologias construtivas em estruturas de concreto armado de edifício com mais de 20 anos de idade
}

\author{
P. Welltten Camargos ${ }^{1 *}$ \\ *Autora de Contato: priscilawelltten@gmail.com \\ ${ }^{1}$ Especialista em Avaliação de Imóveis pela Pontifícia Universidade Católica de Minas Gerais e em Vistoria e \\ Inspeções pelo Instituto Brasileiro de Educação Continuada (Inbec), Belo Horizonte, Brasil
}

\begin{abstract}
RESUMO
Este artigo apresenta e discute os resultados de uma inspeção realizada nos dois níveis que constituem a garagem de um edificio residencial em Belo Horizonte, construído na década de 1990. A inspeção consistiu no levantamento, no registro e na análise das estruturas em concreto armado: lajes, vigas e pilares. Com auxílio de drone, analizou-se a fachada, para identificar visualmente anomalias na estrutura, não sendo realizado nenhum ensaio destrutivo. Aferiu-se que as estruturas apresentavam anomalias devido a falha de estanqueidade, que possibilita a passagem de água pelos poros do concreto e acarreta lixiviação e surgimentos de manchas (eflorescência). Diante do diagnóstico, foram propostas ações inibir a ação da água e tratar os elementos estruturais comprometidos, prolongando a vida útil do edificio.
\end{abstract}

Palavras-chave: inspeção; concreto armado; anomalias; falha de estanqueidade; engenharia diagnóstica.

Citar como: Welltten Camargos, P. (2021), "Avaliação de falhas e vícios construtivos em estruturas de concreto armado de edifício com mais de 20 anos desde a construção" in: XVI Congreso Latinoamericano de Patología de la Construcción e VIII Congreso de Control de Calidad en la Construcción (2021 Congressos CONPAT), Brasil. 


\title{
Evaluación de patologías constructivas en estructuras de hormigón armado en un edificio con más de 20 años de servicio
}

\begin{abstract}
RESUMEN
Este trabajo presenta y discute los resultados de una inspección realizada en los dos niveles que constituyen el garaje de un edificio residencial en Belo Horizonte, construido en la década de 1990. La inspección consistió en el levantamiento, registro y análisis de estructuras de hormigón armado: losas, vigas y pilares. La fachada se analizó mediante un dron para identificar visualmente anomalías en la estructura, sin que se realizaran pruebas destructivas. Se verificó que las estructuras presentaban anomalías por filtración, lo que permite el paso del agua por los poros del hormigón y provoca la lixiviación y la aparición de manchas (eflorescencias). Ante el diagnóstico, se plantearon acciones para inhibir la acción del agua y tratar los elementos estructurales comprometidos, prolongando la vida útil del edificio.
\end{abstract}

Palabras clave: inspección; hormigón armado; anomalías; infiltración; diagnóstico.

\section{Evaluation of constructive pathologies in reinforced concrete structures in a building with more than 20 years of service}

\begin{abstract}
This paper presents and discusses the results of an inspection carried out on the two levels that constitute the garage of a residential building in Belo Horizonte, built in the 1990s. The inspection consisted of surveying, registering and analyzing reinforced concrete structures: slabs, beams and pillars. The façade inspection included a drone guided damage survey to visually identify anomalies in the structure. No destructive testing has being carried out. The governing deterioration mechanism of the structure was leakage, which causes leaching and the appearance of stains (efflorescence). In view of the diagnosis, actions were proposed to inhibit the action of water and treat the compromised structural elements, prolonging the useful life of the building.
\end{abstract}

Keywords: inspection; reinforced concrete; anomalies; infiltrations; diagnostic engineering. 


\section{INTRODUÇÃO}

Ao se projetarem estruturas de concreto armado, é calculável que algumas partes da estrutura - tais como os aparelhos de apoio, caixões, insertos, impermeabilizações e outros, tenham vida útil inferior à do todo. A fim de evitar os graves problemas que podem ser derivados da deterioração dessas partes, é imprescindível que, já no projeto, sejam previstos meios adequados de acesso a toda a estrutura, em especial àqueles componentes cuja vida útil seja mais breve do que a do todo (ABNT, 2003).

As inspeções na estrutura de concreto são um mecanismo da engenharia que visa a determinar a condição das estruturas, definir a vida útil e indicar pontos de manutenção preventiva e corretiva. Ela é uma ferramenta diagnostica essencial durante a etapa de utilização, e sua responsabilidade é do usuário, ou seja, síndicos, administradores de condomínio e moradores.

A durabilidade das estruturas "requer cooperação e esforços coordenados de todos os envolvidos nos processos de projeto, construção e utilização" (ABNT, 2003, p. 19). E, tamanha é a relevância da inspeção dentre os esforços que devem ser empregados para fazer das estruturas mais duráveis, que a norma técnica da ABNT NBR 6118 - Projeto de Estruturas de Concreto - Procedimento, preconiza que "o conjunto de projetos relativos a uma obra deve orientar-se sob uma estratégia explícita que facilite procedimentos de inspeção e manutenção preventiva da construção" (ABNT, 2003, p. 24).

Mais do que isso, previu a norma técnica que, a depender do porte da construção e da agressividade do meio, para algumas estruturas seja cabível a produção, por profissional habilitado e devidamente contratado, um manual de utilização, inspeção e manutenção. Elaborado com base nas informações dos projetos, dos materiais e produtos utilizados e da execução da obra, "deve especificar de forma clara e sucinta, os requisitos básicos para a utilização e a manutenção preventiva, necessárias para garantir a vida útil prevista para a estrutura, conforme indicado na ABNT NBR 5674" (ABNT, 2003, p. 192).

Contudo, não existem, atualmente, normas ou meios que garantam a conservação e o arquivo dos projetos estruturais, sendo essa uma questão de necessária melhoria. Ocorre que a avaliação dos projetos é ponto basilar do trabalho de inspeção.

Assim como os projetos arquitetônicos, que se encontram arquivados nas prefeituras dos municípios no qual foram validados, seria interessante que também o projeto estrutural fosse protocolado e arquivado. Isso poderia garantir maior rastreabilidade e propiciaria a conservação dos edifícios e residências.

Quando de posse dos projetos estruturais, é factível identificar desvios resultantes de obras ou reformas, que possam impactar a capacidade portante de uma determinada estrutura ou elemento. Se, caso contrário, o engenheiro avaliador não tiver acesso aos projetos, será preciso avaliar o histórico da edificação - obras, reformas e melhorias - por meio de uma anamnese com proprietários e/ou responsáveis pela edificação.

Mas, ainda que tenha acesso aos projetos estruturais, é imprescindível que o engenheiro avaliador verificar e revisar as áreas e metragens dos projetos preexistentes.

Buscando contribuir para a identificação das principais anomalias que acometem estruturas de concreto com entre 20 e 30 anos de utilização, este artigo é um estudo de caso, em que são apresentados e discutidos os resultados de uma inspeção realizada nos dois níveis que constituem a garagem de um edificio residencial em Belo Horizonte, construído na década de 1990.

O trabalho pericial seguiu incondicionalmente as determinações dos órgãos regentes no que tange à construção civil, como, por exemplo, Associação Brasileira de Normas Técnicas e Corpo de Bombeiros de Minas Gerais. 
A inspeção consistiu no levantamento, no no registro e na análise das estruturas em concreto armado: lajes, vigas e pilares. Ademais, analisou-se a fachada, com auxílio de imagens captadas por drone, para identificar visualmente anomalias na estrutura, não sendo realizado nenhum ensaio destrutivo.

Apurou-se que as principais causas das anomalias apresentadas pelas estruturas estavam relacionadas a falhas de estanqueidade - o que possibilita a passagem de água pelos poros do concreto e acarreta lixiviação e surgimentos de manchas (eflorescência) - intensificadas por falhas de projeto. Diante do diagnóstico, foi possível propor ações inibir a ação da água e tratar os elementos estruturais comprometidos, prolongando a vida útil do edificio.

\section{ANOMALIAS ESTRUTURAIS}

As anomalias em edificações podem ser causadas tanto por fatores intrínsecos, quanto por fatores extrínsecos. Relacionados a deficiências de projeto ou de execução da obra ou a de falhas de utilização, deterioração natural ou pelo esgotamento da vida útil do componente, os fatores internos são inerentes ao próprio imóvel. Os fatores externos, por sua vez, são produzidos por terceiros, não previstos quando da execução da obra (Ripper e Souza, 1998).

\subsection{Origem da anomalia}

Diversos são os tipos de anomalias que podem fazer com que o usuário solicite uma inspeção em estrutura de concreto armado: sobrecarga, deformações (fissuras, trincas e rachaduras), desplacamento, modificações em projetos, estalos ou barulhos, pontos de corrosão, armadura exposta, estrutura exposta a altas temperaturas, etc.

Diversas também podem ser os fatores dos quais originam tais anomalias (ou avarias): endógenos, exógenos, naturais e funcionais, ou construtivos, congênitos ou adquiridos. A cada uma dessas tipologias de origens corresponde uma definição técnica convencionada.

\subsubsection{Anomalias exógenas}

São aquelas originadas de fatores externos ou decorrentes de ação de terceiros, a exemplo dos choques mecânicos, exposições dos sistemas periciados a gases ou líquidos corrosivos, desgaste excessivo por abrasividade não projetada, explosões por imperícia do usuário etc.

\subsubsection{Anomalias adquiridas}

Ocorrem durante a vida útil dos revestimentos, podendo ser naturais, decorrentes da agressividade do meio, ou decorrentes da ação humana, em função da manutenção inadequada ou realização de interferência incorreta nos revestimentos, danificando as camadas e desencadeando um processo patológico.

\subsubsection{Anomalias congênitas}

Originárias da fase de projeto, erros e omissões de profissionais, como falhas de detalhamento e concepção inadequada dos revestimentos.

\subsubsection{Anomalias construtivas}

São provenientes do emprego de mão de obra despreparada, do uso de produtos não certificados e da ausência de metodologia adequada para assentamento das peças durante a execução da obra.

\subsubsection{Anomalias funcionais}

Derivam do desgaste do material ou da sua degradação após significado tempo de vida do sistema edificante, em uso repetitivo ou contínuo. 


\subsubsection{Anomalias naturais}

Decorrem principalmente, das condições climáticas previsíveis ou não, onde o calor e o sol intensos, o frio excessivo, as chuvas torrenciais, o granizo, as ventanias e as demais ações naturais podem causar avarias ou alterar as condições de funcionamento dos sistemas projetados.

\subsubsection{Anomalias endógenas}

São aquelas originadas do próprio sistema edificante periciado, como erro de projeto, material diverso ao especificado pelo projetista, ou de qualidade, assim como desacerto na execução ou execução descuidada.

\subsection{Falhas e vícios construtivos}

Além da classificação das anomalias de acordo com suas origens, faz-se necessário diferenciar falhas de vícios construtivos. É chamado vício um erro oriundo do processo da edificação. Já a falha é um erro oriundo do processo da manutenção.

\subsubsection{Vícios Construtivos}

São anomalias da construção, vícios por inadequação de qualidade prometida ou esperada, são falhas que tornam o imóvel impróprio para o uso ou lhe diminuem o valor.

\subsubsection{Defeitos}

São falhas que fazem com que o funcionamento de produtos ou serviços afetem ou passem a afetar a saúde e segurança do consumidor. Os vícios ou os defeitos podem ser aparentes ou ocultos (que diminuem, ao longo do tempo, o valor da coisa ou a tornam imprópria ao uso a que se destina). Se o consumidor, no momento da aquisição do serviço ou produto, tivesse conhecimento do vício oculto, poderia pleitear um abatimento no preço ou desistir da compra. Por essa razão,

\subsubsection{Danos}

São consequências dos vícios e defeitos, que, na construção civil, afetam a própria obra, o imóvel vizinho, os bens ou pessoas nele situados, ou, ainda, ainda terceiros (transeuntes e outros).

\subsection{Levantamento de origens das avarias}

Durante os trabalhos periciais, quando constatadas anomalias adquiridas por sobrecarga - como deformações, estalos ou barulho - e exposição da estrutura a altas temperaturas, será imprescindível ter em mãos os projetos estruturais da edificação. Dessa forma, é possível avaliar se a manifestação patológica possui como causa o dimensionamento ou a sobressolicitação do sistema.

No entanto, como já mencionado, mais de $60 \%$ dos imóveis com idade superior a 20 anos não possuem arquivados os projetos estruturais. Essa característica interfere diretamente no custo da análise.

Na ausência de projeto será necessária uma "conversa" com a estrutura. Nessa "conversa", durante a qual tem grande valor a experiência do engenheiro avaliador, busca-se entender o comportamento da estrutura e suas solicitações de carga e tensão. O que os olhos e o conhecimento prévio não forem capazes de determinar, deve ser examinado por meio de ensaios - não destrutivos e/ou destrutivos - específicos, visando, sobretudo, a um levantamento preciso e dimensional das estruturas.

Esse levantamento dará origem ao cadastramento estrutural, que pode ser compreendido como o levantamento das dimensões e disposições dos elementos estruturais e posterior consideração de cargas com base no procedimento executivo adotado. 
Tendo em mãos os projetos estruturais e as memórias de cálculo utilizadas, é possível limitar e abreviar o percurso necessário para o diagnostico final.

\section{ESTUDO DE CASO: PLANO DE INSPEÇÃO}

Para o caso em estudo elegeu-se a inspeção de um edifício residencial de 16 pavimentos, de construção que data da década de 1990, na região Centro-Sul da cidade de Belo Horizonte (Brasil). A opção se deu pelo fato de tratar-se de um caso representativo dos imóveis com idade superior a 20 anos, que compõem parcela importante das estruturas que os engenheiros diagnósticos são chamados a inspecionar, e que, na maioria dos casos, não têm seus projetos estruturais arquivados, representando um desafio a mais para a durabilidade da construção.

A inspeção do edifício foi realizada nos dois níveis que constituem a garagem, a fim de apurar a condição em que se encontravam aas estruturas em concreto armado: vigas, pilares e lajes.

Foi realizada uma inspeção de nível 2, caracterizada pela vistoria para o reconhecimento das anomalias aparentes, por meio de um grupo plurifacetado de especialistas, com auxílio de equipamentos e contando, ao final, com orientação técnica pertinente.

\subsection{Inspeção preliminar}

A primeira e segunda visitas ao empreendimento tiveram como objetivo o levantamento das áreas, e a verificação das metragens dos projetos preexistentes.

\subsection{Inspeção detalhada}

$\mathrm{Na}$ terceira e na quarta visitas, com o apoio do projeto já revisado, houve o mapeamento das anomalias conforme suas localizações, gerando o projeto "Mapeamento de falhas e vícios construtivos", que foi apresentado em duas pranchas, uma para cada nível do estacionamento.

A inspeção consistiu no levantamento e na análise das estruturas em concreto armado (lajes, vigas e pilares), sendo cada uma delas devidamente registrada.

Além disso, a fim de identificar visualmente anomalias na estrutura, houve a análise da fachada com a utilização de drone.

Nenhum ensaio destrutivo foi realizado.

\section{DIAGNÓSTICO E DISCUSSÃO}

Na inspeção realizada verificou-se a degradação dos elementos estruturais - pilares, vigas e lajes - devido à ausência de estanqueidade. Ela ocorreu tanto entre os pavimentos, o que facilitou a percolação de água nas lajes e no encontro das vigas, quanto na base dos pilares, o que corroborou para a percolação de água por capilaridade.

O processo de percolação de água nas estruturas, juntamente com a exposição dos elementos ao $\mathrm{CO}^{2}$ e ao oxigênio, provocou a ocorrência de manifestações patológicas, que, após análise detida, foram classificadas por local e por nível de deterioração, do Nível 00 ao Nível 08, como explicitado:

- Nível 00: ausência de manutenção;

- Nível 01: manchas esbranquiçadas na face inferior devido ao processo de lixiviação do hidróxido de cálcio;

- Nível 02: expansão da frente da carbonatação;

- Nível 03: avanço da frente de carbonatação e influência na camada passivadora existente entre o aço e o concreto;

- Nível 04: corrosão das barras metálicas; 
- Nível 05: formação de trincas no concreto paralelas as armaduras;

- Nível 06: segregação e/ou lascamento superficial da camada de cobrimento;

- Nível 07: exposição das armaduras;

- Nível 08: perda da seção do aço.

Além do nível de deterioração, as anomalias foram avaliadas em relação ao grau de risco que representam, podendo ser crítico, regular ou mínimo.

- Crítico: impacto irrecuperável, relativo ao risco contra a saúde, a segurança do usuário e do meio ambiente, bem como perda excessiva de desempenho. Neste caso, recomenda-se intervenção imediata.

- Regular: impacto parcialmente recuperável, relativo ao risco quanto à perda parcial de funcionalidade e desempenho. Recomendam-se programação e intervenção em curto prazo.

- Mínimo: impacto recuperável, relativo a pequenos prejuízos, sem incidência ou probabilidade de ocorrência dos riscos acima expostos. Recomendam-se programação e intervenção a médio prazo.

Levando em conta o nível de deterioração e o grau de risco das anomalias, bem como seu local de ocorrência, a estrutura acometida e a incidência da anomalia (que pode ser pontual, quando surge em algum ponto da estrutura, ou generalizada, quando incide sobre grande área da estrutura), foi possível elaborar um quadro detalhando cada uma das avarias identificadas em cada uma das estruturas inspecionadas. Ao final, para representar as falhas identificadas e facilitar a compreensão pelos usuários e contratantes da inspeção acerca das anomalias referidas, cada uma delas foi caracterizada por uma foto representativa. Importa destacar que essa caracterização com foto representativa das avarias em tabela não dispensa a apresentação de relatório fotográfico detalhado das anomalias, mas o complementa.

A título de exemplo, na Tabela 1, abaixo, é possível observar a parte do quadro referente às anomalias encontradas nos pilares do primeiro nível. Constam do laudo técnico, contudo, análises semelhantes acerca das anomalias encontradas nas lajes, nos pilares e nas vigas tanto do primeiro, quanto do segundo níveis.

Tabela 1. Nível, grau de risco, incidência, estrutura atingida e caracterização fotográfica das anomalias encontradas nos pilares do $1^{\circ}$ nivel.

\begin{tabular}{|c|c|c|c|c|c|}
\hline Local & $\begin{array}{l}\text { Nível de } \\
\text { deterio- } \\
\text { ração }\end{array}$ & $\begin{array}{l}\text { Grau de } \\
\text { risco }\end{array}$ & $\begin{array}{l}\text { Incidência } \\
\text { da anomalia }\end{array}$ & Estrutura & Caracterização \\
\hline $\begin{array}{c}\text { Pilar } \\
1^{\circ} \text { nível }\end{array}$ & 00 & Mínimo & - & $\begin{array}{c}\text { P10, P11, P15, } \\
\text { P24 }\end{array}$ & \\
\hline
\end{tabular}




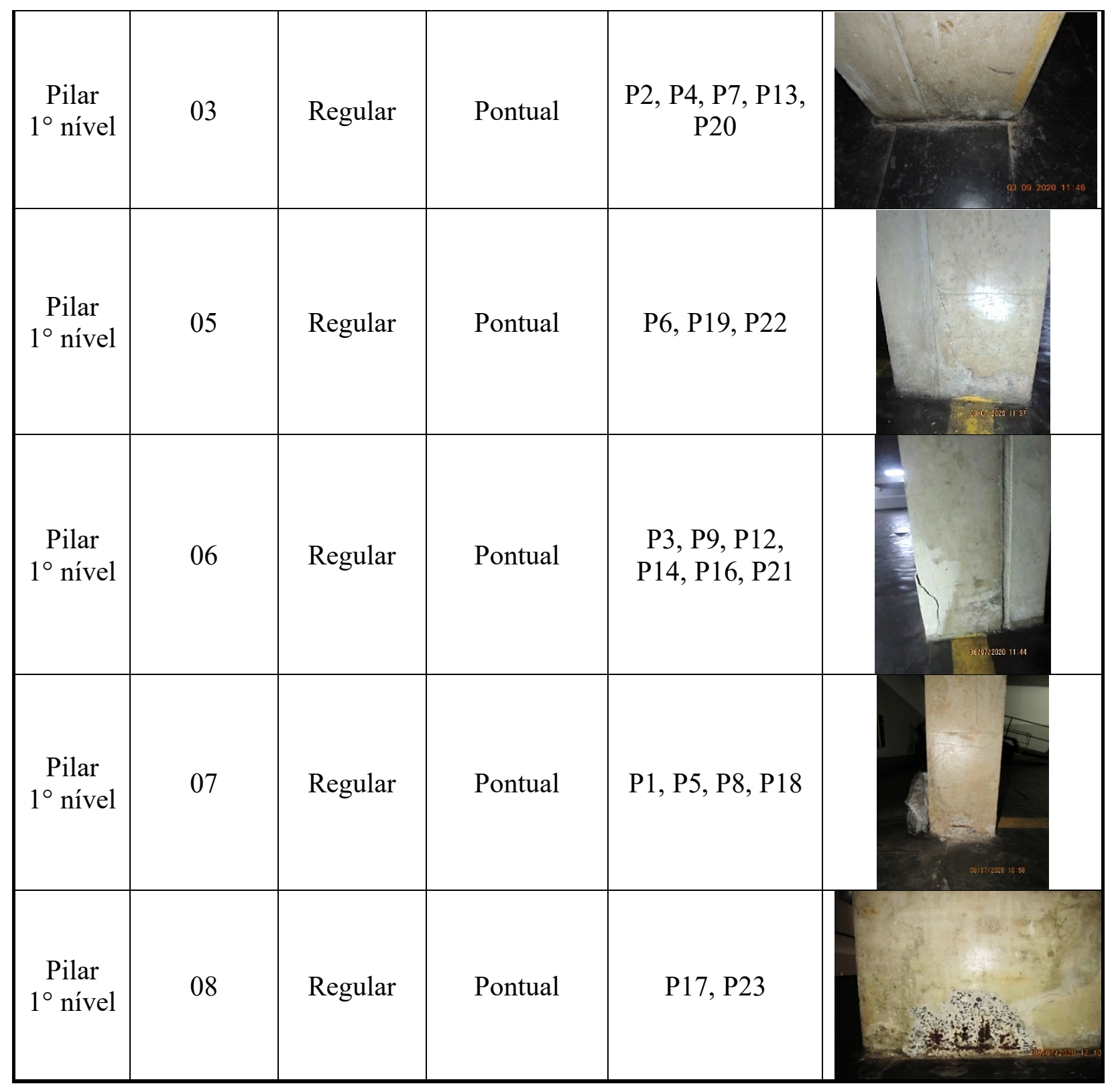

\subsection{Causas}

Quando apuradas condições patológicas relacionadas à corrosão das armaduras, é necessário definir o mecanismo de deterioração. Em estruturas de concreto armado o processo corrosivo pode ocorrer por fatores relacionados ao projeto, à metodologia executiva, ao material, ou à ausência ou ineficácia dos procedimentos de manutenção preventiva e corretiva.

Inicialmente, verificou-se percolação de água através dos poros do concreto da estrutura, acarretando fenômenos que degradam as lajes, as vigas e os pilares. Por essa razão, tendo em vista que a falha se relaciona com a estanqueidade, os agentes causadores das anomalias no edifício inspecionado foram, de pronto, classificados quanto à causa extrínseca.

Quando não há um sistema de impermeabilização que garanta a estanqueidade do local, há o surgimento de anomalias no elemento. Assim, a estrutura da garagem apresenta manchas esbranquiçadas, denominadas eflorescências (como ilustrado na Figura 1.a), e, quando em intensidade e frequência, há formação das estalactites (observáveis na Figura 1.b), o que também foi identificado na laje da garagem. 

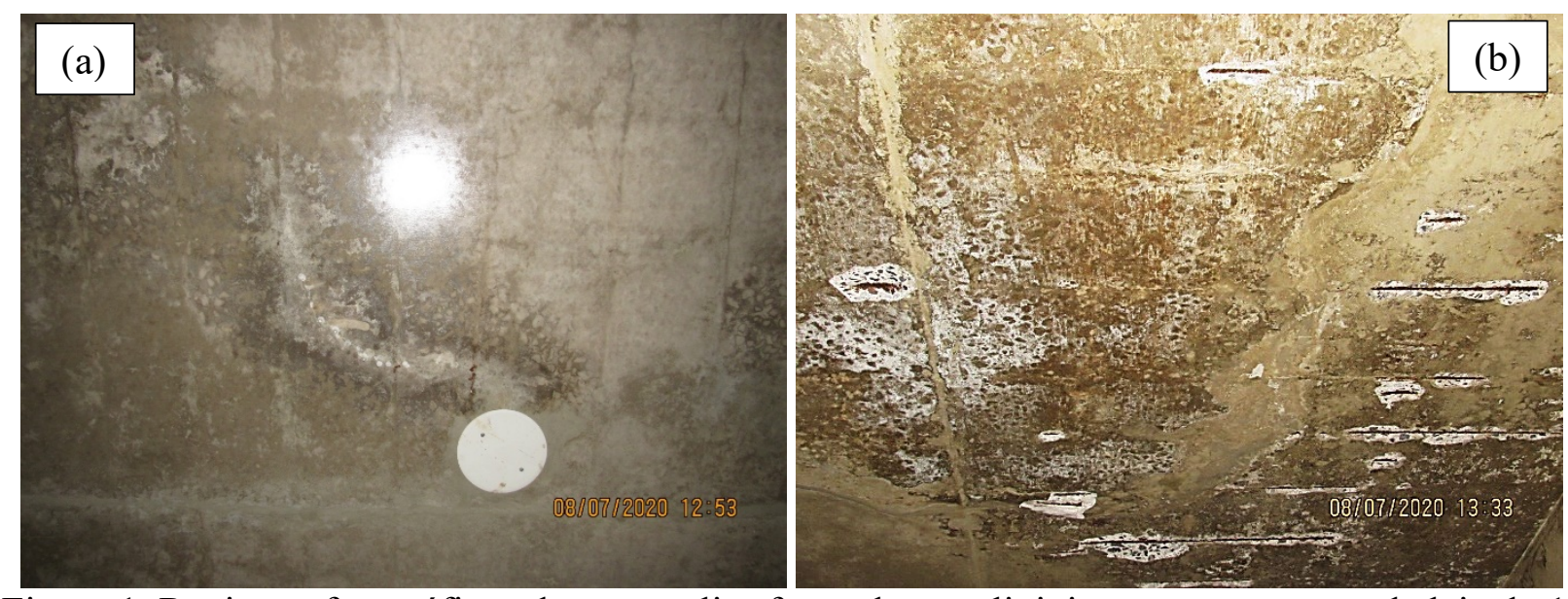

Figura 1. Registros fotográficos das anomalias formadas por lixiviação na estructura da laje do $1^{\circ}$ nivel da garagem: a) eflorescências na laje L12; b) estalactites na laje L10.

Aliadas à falha de estanqueidade, foram identificadas falhas que se associam a causas intrínsecas, uma vez que há a exposição de armaduras devido à falta de cobrimento do concreto destinado à proteção da armadura, como demonstrado na Figura 2. Isso caracteriza a ocorrência de uma falha na etapa de execução da estrutura, além da concentração de gases no ambiente pela falta de ventilação do local.

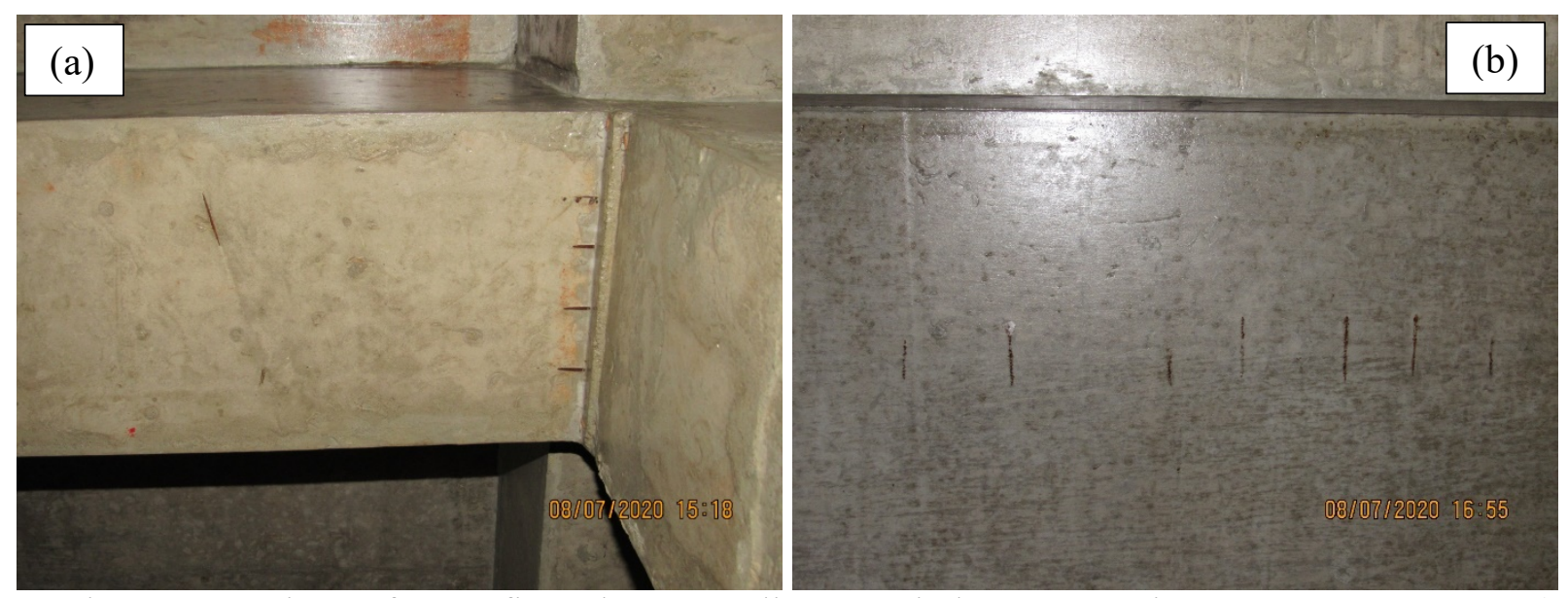

Figura 2. Registros fotográficos das anomalias associadas a causas intrínsecas à estrutura: a) exposição das armaduras na viga V1b, localizada no primeiro nível da garagem; b) exposição das armaduras na laje L12, no segundo nivel da garagem.

A corrosão de armadura é manifestação patológica com um dos maiores índices de ocorrência no concreto armado, sendo que, no Brasil, o índice varia de 14\% a 64\% (Carmona et al., 1988; Dal Molin, 1988; Andrade, 1997). A corrosão implica na redução da área da barra de aço, e consequentemente, na diminuição da capacidade portante da estrutura, além da deterioração estética. Dessa forma, deve ser considerado o estado atual da estrutura e identificar as intervenções apropriadas, a fim de manter a capacidade de desempenho de suas funções.

\subsection{Pilotis}

A área de pilotis encontra-se em um pavimento superior ao $2^{\circ}$ nível de garagem, de modo que as falhas de estanqueidade lá aferidas estão associadas a esse pavimento. No local, durante a aferição por meio de vistoria, notou-se que algumas peças do piso apresentavam som cavo. 
Assim sendo, alertou-se sobre a necessidade de realizar o teste de percussão antes de proceder com metodologia de reparo no piso. Com tal teste será possível identificar as peças que estejam sem aderência ao substrato. Identificadas as peças, elas devem ser removidas e as que se apresentem aproveitáveis devem ser limpas para que, ato contínuo, seja realizado seu reassentamento.

Entre o rejuntamento do piso, foi identificado o crescimento de vegetação, que deve ser removida, assim como o rejunte, para que haja uma nova aplicação de rejunte, conforme indicado nos procedimentos de reparo.

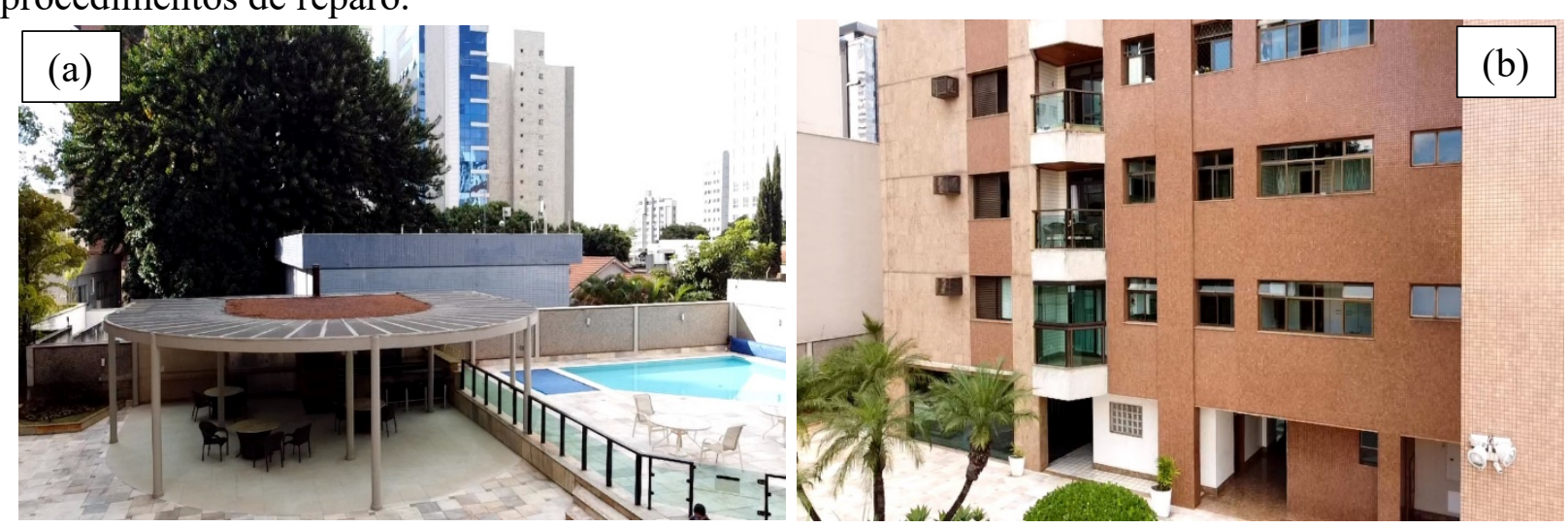

Figura 3. Pavimento Pilotis, que se encontra acima do $2^{\circ}$ nível da garagem: a) local onde serão tratadas as falhas de estanqueidade da laje do $2^{\circ}$ nível da garagem e após teste de percussão no piso; b) vista de pilares existentes no pavimento pilotis.

Considerando que os pilares de sustentação da edificação se encontram no pavimento pilotis, como demonstrado pela Figura 3.b, não é possível conceber um programa de reparação sem que haja a avaliação dessa estrutura. Indicou-se realizar a avaliação do estado atual da estrutura mediante remoção de parte do revestimento.

Alerta-se, contudo, para a possibilidade de perda de peças durante o procedimento, e, dada a indisponibilidade de peças equivalentes no mercado atual, não haver substituição de mesma tonalidade das peças existentes. Calcula-se, porém, que a retirada do revestimento para verificação pontual dos pilares seja imprescindível para um diagnóstico primoroso da situação das estruturas que sustentam o edifício.

\subsection{Fachada}

Com o auxílio de um drone, também a fachada foi objeto de vistoria a fim de identificar anomalias. A vistoria consistiu em uma avaliação visual, não tendo sido realizado nenhum ensaio destrutivo. Todavia, indicou-se, como demonstra a Figura 4.d, a necessidade de executar teste de percussão para um parecer satisfatório, antes de se realizarem as metodologias de reparo a serem efetuadas na fachada.

O teste de percussão visa a mapear a fachada, verificando as peças que apresentam som cavo devido a falhas de aderências ao substrato. Em seguida ao teste de percussão, as peças identificadas com falha de aderência, devem ser removidas e, quando for possível realizar o seu aproveitamento, deve ser realizada a limpeza do tardoz da peça, para posteriormente realizar novo assentamento da peça. Nas varandas dos apartamentos localizadas junto à fachada, foi verificada a formação de trincas junto ao revestimento (Figura 4.e). Para sua tratativa, após a execução de limpeza do revestimento é indicável a aplicação de um produto a fim de promover a vedação, conforme será indicado nos procedimentos de reparos. No que tange às vigas de bordas localizadas no último pavimento, há grande incidência de trincas, e a aferição das armaduras se faz necessária. Dessa forma, não foi indicada nenhuma metodologia de reparo para o local. É necessário que primeiro haja a quebra do 
concreto para verificar as condições das barras de aço que se encontram no interior. Ou, ainda, pode ser realizado o ensaio de potencial de corrosão, para mesma aferição.

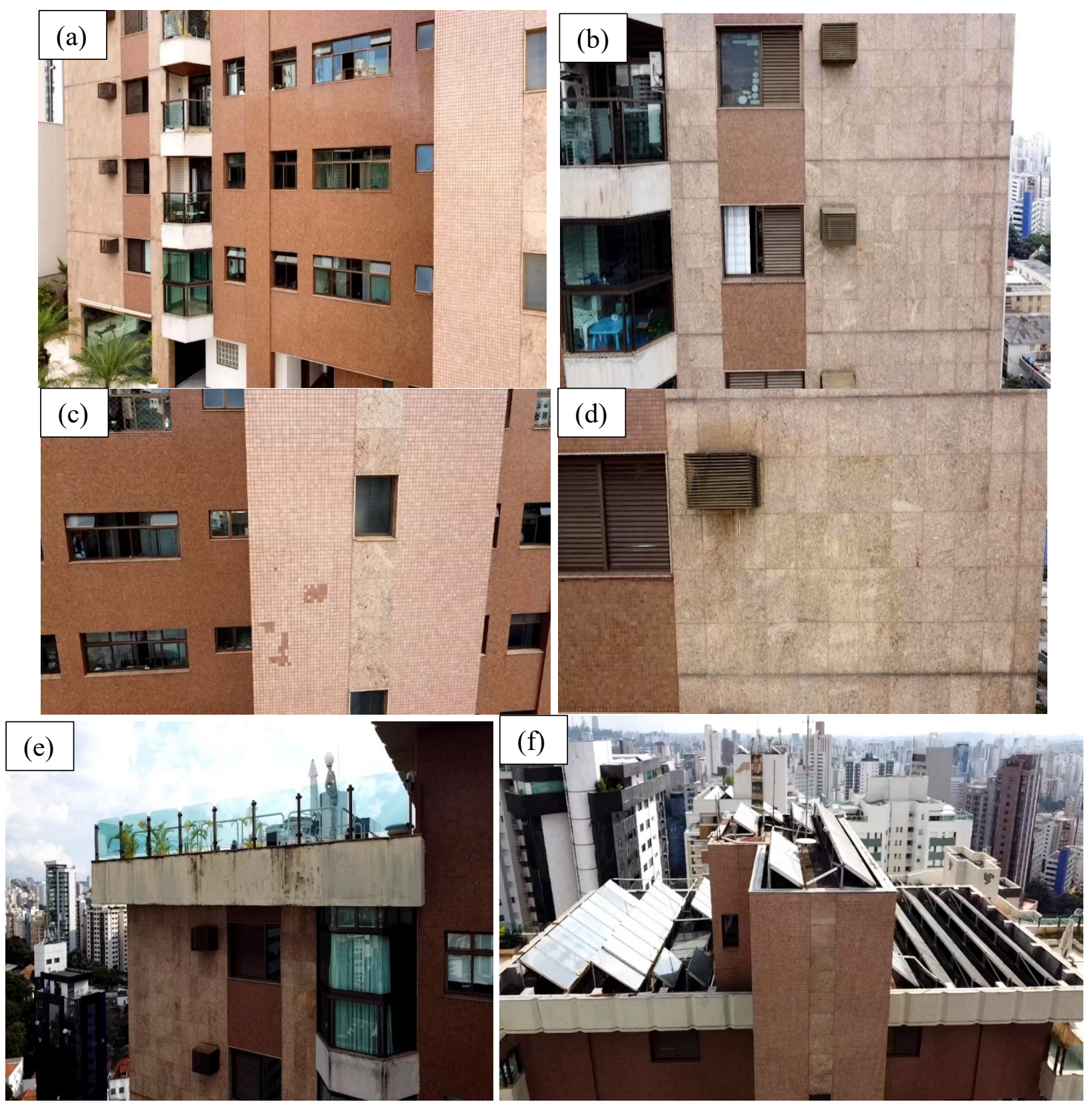

Figura 4. Vistorias da fachada capturada com o auxílio de drone: a) vista da fachada posterior; b) revestimento em pedras de granito; c) na fachada já houve recomposição do revestimento em pastinha que se deu em outra tonalidade; d) manchas no revestimento das pedras. Indica-se a realização do teste a percussão para verificação da aderência das peças; e) devido à presença de manchas e trincas, é necessário realizar a quebra do material ou um ensaio de potencial de corrosão, de modo a aferir as barras de aços no interior do concreto; f) vista da cobertura.

\section{LEVANTAMENTO QUANTITATIVO DAS ESTRUTURAS}

A partir de levantamento do, vistoria e avaliação das estruturas, foi possível classificá-las de 00 a 08, de acordo com os níveis de deterioração estrutural que apresentavam. Com base nesses dados, 
elaborou-se a Tabela 2, que apresenta o quantitativo referente à área de laje, ao comprimento de viga e à quantidade de pilares totais que apresentavam avarias de cada nível de deterioração.

Esse levantamento quantitativo é de grande importância para que se tenha uma visão geral da extensão e complexidade das obras necessárias a tratar das estruturas do edifício que estejam com avarias.

Tabela 2. Quantitativo das estruturas.

As unidades de medida utilizadas são: a) laje: $\mathrm{m}^{2}$; b) viga: $\mathrm{m}$; c) pilar: unidade.

\begin{tabular}{|c|c|c|c|c|c|c|c|c|c|}
\hline NIVEL & 00 & 01 & 02 & 03 & 04 & 05 & 06 & 07 & 08 \\
\hline $\begin{array}{c}\text { Laje } \\
1^{\circ} \text { nível } \\
\text { (anomalia } \\
\text { pontual) }\end{array}$ & 799,30 & 19,16 & - & - & - & - & 1,44 & 51,82 & 0,40 \\
\hline $\begin{array}{c}\text { Laje } \\
1^{\circ} \text { nível } \\
\text { (anomalia } \\
\text { generalizada) }\end{array}$ & - & - & - & - & - & - & - & 3,32 & 2,23 \\
\hline $\begin{array}{c}\text { Viga } \\
1^{\circ} \text { nível } \\
\end{array}$ & 280,48 & 14,69 & - & - & - & - & - & 33,86 & - \\
\hline $\begin{array}{c}\text { Pilar } \\
1^{\circ} \text { nível }\end{array}$ & 24 unid & & & $\begin{array}{c}4 \text { unid } \\
(25 \times 25) \\
1 \text { unid } \\
(66 \times 100)\end{array}$ & & $\begin{array}{c}1 \text { unid } \\
(25 \times 25) \\
1 \text { unid } \\
(45 \times 120) \\
1 \text { unid } \\
(35 \times 113)\end{array}$ & $\begin{array}{c}5 \text { unid } \\
(25 \times 25) \\
1 \text { unid } \\
(116 \times 33)\end{array}$ & $\begin{array}{c}3 \text { unid } \\
(25 \times 25) \\
1 \text { unid } \\
(60 \times 100)\end{array}$ & $\begin{array}{c}1 \text { unid } \\
(120 \times 30) \\
1 \text { unid } \\
(25 \times 110)\end{array}$ \\
\hline $\begin{array}{c}\text { Laje } \\
2^{\circ} \text { nível } \\
\text { (anomalia } \\
\text { pontual) }\end{array}$ & 1643,78 & 13,77 & - & - & 5,79 & - & 6,74 & 29,34 & - \\
\hline $\begin{array}{c}\text { Laje } \\
2^{\circ} \text { nível } \\
\text { (anomalia } \\
\text { generalizada) }\end{array}$ & - & - & - & - & - & - & - & 6,6 & - \\
\hline $\begin{array}{c}\text { Viga } \\
2^{\circ} \text { nível }\end{array}$ & 770,22 & 60,15 & - & - & 11,76 & 4,8 & 30,71 & 49,69 & 4,55 \\
\hline $\begin{array}{c}\text { Pilar } \\
2^{\circ} \text { nível }\end{array}$ & 70 unid & - & - & $\begin{array}{c}3 \text { unid } \\
(25 \times 25) \\
1 \text { unid } \\
(30 \times 100) \\
1 \text { unid } \\
(25 \times 50) \\
2 \text { unid } \\
(40 \times 100)\end{array}$ & $\begin{array}{c}3 \text { unid } \\
(25 \times 25) \\
3 \text { unid } \\
(100 \times 30) \\
1 \text { unid } \\
(45 \times 100) \\
1 \text { unid } \\
(65 \times 25)\end{array}$ & $\begin{array}{c}3 \text { unid } \\
(25 \times 25) \\
1 \text { unid } \\
(8025) \\
2 \text { unid } \\
(25 \times 50)\end{array}$ & $\begin{array}{c}2 \text { unid } \\
(25 \times 25) \\
2 \text { unid } \\
(100 \times 30) \\
1 \text { unid } \\
(40 \times 100)\end{array}$ & $\begin{array}{c}2 \text { unid } \\
(25 \times 25) \\
1 \text { unid } \\
(35 \times 25) \\
1 \text { unid } \\
(35 \times 35) \\
1 \text { unid } \\
(35 \times 110)\end{array}$ & $\begin{array}{c}1 \text { unid } \\
(25 \times 110) \\
1 \text { unid } \\
(25 \times 50)\end{array}$ \\
\hline
\end{tabular}

Destaca-se que a tratativa a ser realizada nas estruturas cujas avarias sejam de nível 00 refere-se ao tratamento superficial no concreto, tratativa esta que será aplicada também a todas as estruturas, após respectivos tratamentos de recuperação indicados. 


\section{ALTERNATIVAS DE REPARO}

Após a realização da vistoria, propuseram-se distintas metodologias para adequadamente tratar as estruturas de concreto armado, de acordo com as anomalias apresentadas por cada uma.

O procedimento de impermeabilização deve ser realizado no $2^{\circ}$ nível de garagem e no pilotis. A proteção superficial de concreto é indicada para todas as lajes em sua face inferior, assim como para todos os pilares e vigas em toda sua extensão.

Os tratamentos de recuperação somente devem ser realizados nas estruturas com indícios de corrosão e com manifestações patológicas decorrentes desse fenômeno, sendo adotado o tipo 01. E, quando identificada a perda de seção superior a 10\%, recomendou-se a adoção do tipo 02 .

No que diz respeito ao tratamento da fachada que não esteja relacionado a falhas estruturais, indicou-se a aplicação de procedimento de proteção superficial, o mesmo cabendo para as varandas.

Na tabela abaixo, é possível observar a relação entre anomalias, o tratamento a elas indicado e as opções para viabilização dessa metodologia.

Tabela 3. Tratativas relacionadas às estruturas de concreto armado.

\begin{tabular}{|c|c|c|}
\hline Anomalias & Tratamento & Opções \\
\hline Eflorescência e manchas - Nível 00 & $\begin{array}{l}\text { Impermeabilização ou melhora } \\
\text { da drenagem }\end{array}$ & $\begin{array}{l}\text { Manta asfáltica ou membrana de } \\
\text { poliuretano }\end{array}$ \\
\hline $\begin{array}{l}\text { Carbonatação superficial (sem } \\
\text { indícios de corrosão) }\end{array}$ & Tratamento superficial & MC-Color Proof Pure - Emcephob WM \\
\hline $\begin{array}{l}\text { Carbonatação superficial (com } \\
\text { corrosão) }\end{array}$ & Tratamento semi profundo & $\begin{array}{l}\text { Detalhe especificado no item de } \\
\text { recuperação estrutural tipo } 01\end{array}$ \\
\hline Corrosão com perda de seção do aço & Tratamento profundo & $\begin{array}{l}\text { Detalhe especificado no item de } \\
\text { recuperação estrutural tipo } 02\end{array}$ \\
\hline $\begin{array}{l}\text { Ausência ou deficiência de } \\
\text { estanqueidade garagens }\end{array}$ & $\begin{array}{l}\text { Impermeabilização ou melhora } \\
\text { da drenagem }\end{array}$ & $\begin{array}{l}\text { Manta asfáltica ou membrana } \\
\text { poliuretano ou pintura tipo epóxi }\end{array}$ \\
\hline $\begin{array}{l}\text { Ausência ou deficiência } \\
\text { estanqueidade pilotis }\end{array}$ & $\begin{array}{l}\text { 1)Rejuntamento das pedras } \\
\text { 2) Impermeabilização da área } \\
\text { integral }\end{array}$ & $\begin{array}{l}\text { Manta asfáltica ou membrana } \\
\text { poliuretano }\end{array}$ \\
\hline $\begin{array}{l}\text { Proteção das vigas, pilares e lajes } \\
\text { (sem indícios de anomalias) }\end{array}$ & Tratamento superficial & $\begin{array}{l}\text { Detalhe especificado no item de } \\
\text { proteção superficial concreto tipo } 01\end{array}$ \\
\hline Proteção da fachada & $\begin{array}{l}\text { 1)Lavagem da fachada } \\
\text { 2) Novo rejuntamento das } \\
\text { peças } \\
\text { 3) Tratamento superficial }\end{array}$ & $\begin{array}{l}\text { Detalhe especificado no item de } \\
\text { proteção superficial fachada tipo } 01\end{array}$ \\
\hline Varandas dos apartamentos & Tratamento superficial & $\begin{array}{l}\text { Detalhe especificado no item de } \\
\text { proteção superficial concreto tipo } 01\end{array}$ \\
\hline
\end{tabular}

\section{CONCLUSÕES}

A vida útil da estrutura compreende o período durante o qual a estrutura mantém um limite mínimo de serviço para qual foi projetada. Quando a estrutura se encontra deteriorada deve ser implementado um programa de reparo e recuperação, antes que alcance um nível inaceitável. A inspeção é uma ferramenta para verificar o estágio atual das estruturas e, assim, traçar as melhores 
estratégias para tratar adequadamente as partes avariadas, prolongando a vida útil das estruturas de concreto armado.

Neste artigo, como forma de contribuir para a compreensão das anomalias mais comuns em estruturas de concreto armado com entre 20 e 30 anos de idade, realizou-se um estudo de caso baseado na inspeção de edifício residencial localizado na região Centro-Sul de Belo Horizonte-MG (Brasil). A vistoria consistiu no levantamento in loco das regiões e das anomalias identificadas nas áreas de garagem, que compõem os níveis $1^{\circ}$ e $2^{\circ}$ do empreendimento, a fim de propor técnicas e a metodologia a serem empregadas para reparo das estruturas.

Foi aferido que as estruturas de concreto armado que constituem as áreas de garagem, tais como as vigas, pilares e lajes, apresentam anomalias devido a falha de estanqueidade, que possibilita a passagem de água pelos poros do concreto e acarreta na lixiviação e surgimentos de manchas (eflorescência). Houve a degradação do concreto armado, devido ao processo de carbonatação, com o qual instaurou-se o fenômeno de corrosão das barras de aço no interior do elemento. Todo esse processo resulta em produtos de óxidos de ferro que expandem e fraturam o concreto, provocando manifestações patológicas visíveis no concreto: lascamento do concreto, manchas marrom-avermelhadas e fissuração.

Em vista do cenário encontrado, dá-se a necessidade de recuperação da estrutura, uma vez que os fenômenos nela implantados têm potencial de redução da resistência portante. Dessa forma, foi indicada metodologia a ser executada a fim de inibir a ação da água e tratar os elementos estruturais comprometidos. Quanto às fachadas e varandas, foi verificado que não havia comprometimento do sistema construtivo, sendo indicado somente procedimentos de proteção.

$\mathrm{O}$ ingresso de agentes agressivos no interior do concreto pode estar relacionado ao projeto, quanto ao posicionamento e cobrimento das barras metálicas; ao material, quanto à qualidade do adensamento e à relação água/cimento; e às etapas de manutenção, tendo como base agravante ao mecanismo de deterioração as influências do meio ambiente e a localização do elemento estrutural. A concentração de $\mathrm{Co} 2$, a umidade relativa do ar, a temperatura e a condição química do cimento podem acelerar o avanço da frente de carbonatação.

A penetração de substâncias como a água, $\mathrm{CO} 2$ e o oxigênio é facilitada pela da rede de poros e fissuras, elementos que promovem a carbonatação do concreto (a condição inicial da corrosão das armaduras), que ocorre pela penetração do gás carbônico ao longo da camada de concreto até atingir as barras de aço. Embora a carbonatação seja um processo lento, quando não impossibilitado seu avanço para o interior do concreto, esta ação reduz o pH do concreto a níveis insuficientes para manter o estado passivo das armaduras, formando uma corrosão generalizada na barra de aço. Desse modo, a identificação e análise das manifestações patológicas em estruturas de concreto armado, em especial naquelas que, como $60 \%$ dos edifícios com mais de 20 anos, não têm seus projetos estruturais registrados, é essencial para a manutenção de sua vida útil. Apenas com o olhar técnico atento é possível "conversar" com a estrutura para entender suas solicitações de carga e tensão e avaliar as ações necessárias para corrigir eventuais anomalias.

\section{REFERENCIAS}

Andrade, J. (1997), "Durabilidade das estruturas de concreto armado: análise das manifestações patológicas nas estruturas no Estado de Pernambuco.”, dissertação de mestrado, mestrado em Engenharia, Universidade Federal do Rio Grande do Sul.

Associação Brasileira de Normas Técnicas. (2003), NBR 6118: Projeto de estruturas de concreto - Procedimento. Rio de Janeiro. 
Carmona Filho, A., Marega, A. (1988), "A retrospectiva da patologia no Brasil: estudo estatístico" in: Trabajos apresentados em la Jornada Español y Portugues sobre Estructuras y Materiales. Madrid, CEDEX/ICcET, pp. 99-124.

Dal Molin, D.C.C. (1988), "Fissuras em estruturas de concreto armado: análise das manifestações típicas e levantamento de casos ocorridos no Estado do Rio Grande do Sul”, dissertação de mestrado em Engenharia, Universidade Federal do Rio Grande do Sul.

Fortes, F. J. (1994), "Patologia e terapêutica das construções: um panorama. Revista da 'Jornada Professor Hernani Sobral", Salvador.

Lorensini, R.V. (2006), "Avaliação probabilística da deterioração de estruturas em concreto armado". Belo Horizonte, Universidade Federal de Minas Gerais, UFMG.

Ollivier, J.P., Vichot, A. (2014), "Durabilidade do concreto: Bases cientificas para a formulação de concretos duráveis de acordo com o ambiente", Ed tradução: Cascudo, O., Caraesk, H. São Paulo, IBRACON.

Red Rehabilitar. (2003), "Manual de Reabilitação de Estruturas de Concreto: Reparo, Reforço e Proteção”, editores. São Paulo, 2003.

Ripper, T., Souza, V. C. M. (1998), "Patologia, recuperação e reforço de estruturas de concreto”, São Paulo, Pini. 